\title{
Charlie M syndrome
}

INSERM

\section{Source}

INSERM. (1999). Orphanet: an online rare disease and orphan drug data base. Charlie M syndrome. ORPHA:1406

Charlie $\mathrm{M}$ syndrome is a rare bone developmental disorder which belongs to a group of oromandibular limb hypogenesis syndromes that includes hypoglossia-hypodactyly and glossopalatine ankylosis (see these terms). The major anomalies which occur commonly in this group are hypoplasia of the mandible, syndactyly and ectrodactyly, small mouth, cleft palate, hypodontia, and facial paralysis. Patients with Charlie M syndrome also present with hypertelorism, absent or conically crowned incisors, and variable degrees of hypodactyly of the hands and feet. There have been no further descriptions in the literature since 1976. 